\title{
Concerns voiced by patients and GPs' responses during psychosocial visits in primary care: a historical cross-sectional study
}

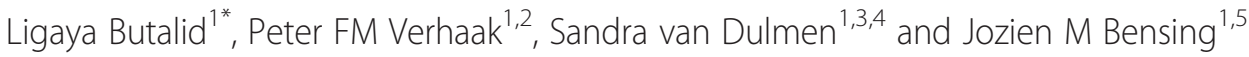

\begin{abstract}
Background: In a recent study comparing psychosocial consultations prior to and after the implementation of national clinical guidelines in the Netherlands, we found that general practitioners (GPs) showed less empathy in the more recent consultations. As a consequence, patients possibly have less scope to express their worries. The objective is to investigate whether patients have become more reluctant to open up about their concerns during psychosocial consultations and how GPs respond.
\end{abstract}

Methods: Consultations from previous study samples videotaped between 1977 and 2008 and categorized by GPs as 'completely psychosocial' were selected for the present study. These consultations were observed using the Verona Coding Definitions of Emotional Sequences (VR-CoDES) to capture cues and concerns expressed by patients and GPs' immediate responses. We compared consultations prior to $(N=121)$ and after $(N=391)$ introduction of national clinical guidelines in the 1990s.

Results: In $92 \%$ of the consultations, patients presented at least one worry. These were most often expressed implicitly. However, the proportion of consultations containing at least one explicit concern changed from $24 \%$ to $37 \%$ over time. The increased number of expressed cues and concerns was partly explained by a change in GP characteristics; the latter sample contained more female and more experienced GPs. Furthermore, cues and concerns were more often expressed during later phases of consultations in recent years.

Conclusions: Our study shows that patients have become somewhat more explicit in expressing their worries. However, GPs need to be aware that, still, most worries are expressed implicitly and that new concerns may appear towards the end of consultations.

Keywords: Doctor-patient relations, General practice, Cues, Empathy, Psychosocial factors

\section{Background}

In a recent comparison between consultations prior to and after the implementation in the 1990s of national clinical guidelines in the Netherlands, general practitioners (GPs) showed less empathy during more recent consultations considered psychosocial by GPs as compared to similar consultations from the 1980s [1]. There has been a shift over time towards greater emphasis on structured questioning, giving information or advice, and providing less emotional support by showing empathy

\footnotetext{
*Correspondence: I.butalid@gmail.com

${ }^{1}$ NIVEL, Netherlands Institute for Health Services Research, Utrecht, The Netherlands

Full list of author information is available at the end of the article
}

$[1,2]$. In recent years, an integrative approach of understanding patients within their personal contexts seems to have been replaced by a more evidence-based approach characterized by active symptom exploration (see Table 1 ). As a consequence, patients may feel less inclined to share their worries.

To adequately handle psychosocial problems, GPs rely on the expression of emotions by their patients. Most expressed emotions relate to psychosocial issues such as depressive feelings, stress or concerns about life changes [3]. However, patients are likely to express implicit cues to underlying emotions and worries, rather than voicing emotional problems explicitly and spontaneously [4]. These implicit cues are often vague and ambiguous and 
Table 1 The changing context of discussing psychosocial problems in primary care

\begin{tabular}{lll}
\hline Approach & Main focus & Background \\
\hline Integrative & $\begin{array}{l}\text { What is the meaning of the } \\
\text { illness for the patient? }\end{array}$ & $\begin{array}{l}\text { In 1959, the Dutch College of General Practitioners stated that general practice care had to be } \\
\text { continuous, integrative and personal.' Under this agreement, GP care was explicitly placed in a } \\
\text { broader societal and emotional context and not limited to a biomedical framework. In the years } \\
\text { that followed, and more specifically during the 1970s and 1980s, there was greater emphasis on the } \\
\text { importance of understanding patients within their personal contexts and GPs were encouraged } \\
\text { to let patients talk freely during consultations. Rogers' client-centered approach }{ }^{2} \text { - in which } \\
\text { empathy and unconditional positive regard were keywords - was used as a framework for } \\
\text { dealing with psychosocial problems in general practice. }\end{array}$ \\
& $\begin{array}{ll}\text { From the 1990s, more emphasis was placed on evidence-based medicine with the introduction } \\
\text { of clinical guidelines in Dutch general practice. These guidelines mostly emphasized active } \\
\text { symptom exploration by GPs. In 1994, the Dutch College of General Practitioners published } \\
\text { the national clinical guideline for depression. }{ }^{3} \text { Today, there are eight clinical guidelines specifically } \\
\text { for psychological problems and the use of guidelines is widely implemented in general practice in } \\
\text { the Netherlands. }\end{array}$
\end{tabular}

${ }^{1}$ Nederlands Huisartsen Genootschap, Commissie Wetenschappelijk Onderzoek (1959). Woudschotenrapport: Rapport over de taak van de huisarts, de zogenaamde Woudschotenmaterie [Woudschoten report: Report on the role of the general practitioner].Utrecht:NHG.

${ }^{2}$ Rogers CR. (1961). On becoming a person. A therapist's view of psychotherapy. Boston: Houghton Mifflin.

${ }^{3}$ Van Marwijk, H.W.J., Grundmeijer, H.G.L.M., Bruerer, M.M., Sigling, H.O., Stolk, J., Van Gelderen, M.G., Vintges, M., Eizenga, W.H., Burgers, J.S. (1994). NHG-standaard

Depressie [Clinical guideline depression of the Dutch College of General Practitioners]. Huisarts en Wetenschap, 37, 482-490.

${ }^{4}$ Nederlands Huisartsen Genootschap (2013). NHG-standaarden. Retrieved from: https://www.nhg.org/nhg-standaarden.

require further exploration by the GP and empathy from GPs may encourage patients to be more open and direct in further expressions of their worries [5]. Addressing and responding to patients' emotions and psychosocial issues early on during consultations may reduce the tendency for patients to wait to express remaining problems or concerns until the closing stages of the visit [6].

Because of the previously found reduction in empathy showed by GPs, new questions arise regarding the role of patients during consultations. It can be argued that patients' manner of communicating has changed over time like GPs' communication styles have. Patients may have become less explicit in sharing their concerns, which could explain the decrease in empathy by GPs. Despite a broad consensus on the importance of activating patients and increasing their autonomy in health care [7], patients do not seem to be as participatory as expected during consultations [2]. Moreover, studies on the closing phase of general practice consultations show that patients often present 'doorknob' concerns [6]. It can be argued that if patients have indeed become more reluctant to share their worries in recent years, they may postpone expressing their concerns until later phases of the consultations. On the other hand, the emphasis put on active symptom exploration with the introduction of Dutch clinical guidelines in general practice may motivate GPs to actively invite patients to share their concerns regarding psychosocial problems during the earlier, diagnostic, phase of consultations.

\section{Aims of the study}

We aim to study the role of patients during psychosocial consultations prior to and after the introduction of guidelines on psychological disorders in Dutch general practice in the 1990s. We decided to further investigate previously examined consultations that were considered psychosocial by GPs [1], and focus on whether patients share their worries and how GPs respond to these worries.

First, given the previously found decline in empathy by GPs over time, we expect to find a decline in expression of concerns or cues to underlying concerns by patients during recent consultations. Second, we aim to explore the timing of expressed worries of patients during consultations from the two time periods. Greater reluctance among patients to share their worries may also imply postponement of expressing concerns. On the other hand, active symptom exploration may motivate GPs to invite patients to share concerns during diagnostic phases of consultations. Last, we expect that GPs have become less responsive and inviting to patients' worries.

\section{Methods}

\section{Videotaped consultations}

Dutch general practice consultations were videotaped in the period from 1977 to 2008 as part of previous studies on doctor-patient communication [8-13]. Participating GPs were followed for at least a full day (or a series of consecutive days). An unmanned camera was placed in the consultation room to record consultations. A research assistant was present in the waiting room to ask patients' informed consent for participating in the study and answer any additional questions. All participating GPs and patients provided some general background information in a basic questionnaire (e.g. age, gender, assessment of psychosocial aspects), which enabled the selection of consultations for additional observational research in the present study. We included consultations from six previous study samples (1977-1980, 1982-1984, 
1989, 1995, 2000-2001, 2007-2008) and assigned these samples to the two periods of interest (prior to clinical guidelines: 1977-1980, 1982-1984, 1989, versus after the introduction of guidelines: 1995, 2000-2001, 2007-2008). The total database of available videotaped consultations consisted of 5,184 consultations (1,895 in the first period, 3,289 in the second period). First, the GP from each videotaped consultation assessed the degree to which psychosocial aspects determined the consultation ( $1=$ completely somatic; 2 = mainly somatic; 3 = both somatic and psychosocial; 4 =mainly psychosocial; $5=$ completely psychosocial). Second, we selected consultations assessed by the GP as being 'completely psychosocial'. GPs assessed 150 consultations in the first period and 394 consultations in the second period as psychosocial. Owing to deterioration in the technical quality of some videotaped consultations, we excluded 31 consultations ( 28 in the first period, 3 in the second period) and one consultation was excluded because patient characteristics (e.g. age) were not available. Our analyses were conducted on 512 consultations (121 in the first period, 391 in the second period) and we specified whether psychological $(\mathrm{N}=185)$, social $(\mathrm{N}=62)$ or physical $(\mathrm{N}=265)$ symptoms were presented by patients during these consultations by using the International Classification for Primary Care (ICPC) codes that were available for all consultations in the database.

The studies were carried out in accordance with Dutch privacy legislation. The privacy regulations were approved by the Dutch Data Protection Authority. According to Dutch legislation, approval by a medical ethics committee was not required for these observational studies. All participating physicians and patients gave their informed consent.

\section{Measures of communicative behaviour}

Patient cues and concerns were coded using the Verona coding definitions of emotional sequences, VR-CoDES-CC [14]. A cue is defined as 'a verbal or non-verbal hint which suggests an underlying unpleasant emotion but lacks clarity' ("I cannot stand it anymore"), while a concern is 'a clear and unambiguous expression of an unpleasant current or recent emotion where the emotion is explicitly verbalized' ("I feel very anxious"). GPs' immediate responses (lag 1) to cues and concerns were coded using VR-CoDES-P [15]. We only coded lag 1 responses, which refers to the first utterance after a voiced cue or concern, while excluding delayed responses (e.g. lag 2 or 3). Responses were coded according to two major conceptual factors: explicitness (explicit versus non-explicit responses) and space provision for further disclosure of the cue of concern (space-providing versus spacereducing responses). See Table 2 for definitions and examples of the response categories.

Approximately $10 \%$ of the observed consultations were coded by the two coders involved in this study. The interrater reliability of the VR-CoDES-CC and VRCoDES-P was found to be satisfactory to good. We calculated an intraclass correlation (ICC) of 0.56 for concerns and 0.89 for cues. The mean intraclass correlation of the GPs' response categories was 0.71 (range $0.43-0.86)$.

Total visit duration was timed in seconds for all videotaped consultations in the database. We timed the initial opening statements by patients, which starts after GPs solicitations ("What can I do for you today?") and ends when GPs initiate the next phase of exploration by asking either open-ended ("Tell me more about the head aches") or closed-ended questions ("Is it worse in the morning or in the evening?"). The last phase of the consultation can be considered the therapeutic phase of the consultation and is characterized by GPs giving information and advice. The interrater reliability of the durations of the different phases during consultations (initial opening statements, exploration including physical examination, and giving information and advice) was found to be good. The mean intraclass correlation of the duration of the phases was 0.93 (range $0.90-0.99$ ).

\section{Statistical analyses}

To account for the variation in communication skills between GPs, we used multilevel models with random intercepts (multilevel Poisson regression analysis for count variables). The multilevel models consisted of consultations (level 1) nested within GPs (level 2). The number of consultations per GP in the sample varied between 1 and 15 . However, since $80 \%$ of the GPs had five or less consultations included in the present study, we could not calculate or report on intraclass correlations. We included dummy variables for both periods (1977-1989 versus 1995-2008) and examined estimated frequencies for the three types of symptoms (psychological, social and physical symptoms). First, we used multilevel Poisson regression models to estimate frequencies of communication categories by GPs per consultation. In these analyses, we included duration of consultation, patient characteristics and GP characteristics as centred covariates. Second, based on these estimates we tested whether there were differences in communication categories between the two periods.

\section{Results}

\section{Consultation characteristics}

Mean duration of consultations in the second period (1995-2008) was significantly longer than during than in the first period (see Table 3). When comparing the patient and GP characteristics between the two time periods, we found that patients and GPs were significantly older in 1995-2008 compared to 1977-1989. The gender ratios of patients did not differ significantly 
Table 2 Response categories by GPs according to VR-CODES-P

\begin{tabular}{|c|c|c|}
\hline \multicolumn{3}{|l|}{ Non-explicit, reducing space } \\
\hline Ignore & No reference is made whatsoever to the concern & \\
\hline Shutting down & Denying patient's concern & "Oh don't be silly" \\
\hline Information advice & $\begin{array}{l}\text { Giving information or advice in a way that does not } \\
\text { open space for further disclosure }\end{array}$ & "Headaches are very common" \\
\hline \multicolumn{3}{|c|}{ Non-explicit, providing space } \\
\hline Silence & Silence to invite patient to talk about the concern & \\
\hline Back channel & Minimal prompt to invite patient to talk about the concern & "Hmm" "Ok..." \\
\hline Acknowledgement & Implicit comment beyond the minimal back channel & "I can see that" \\
\hline Active invitation & Clearly inviting, but implicit in relation to the concern & "Would you like to tell me more?" \\
\hline Implicit empathy & $\begin{array}{l}\text { Expression of feeling or understanding, without explicit } \\
\text { reference to the concern }\end{array}$ & "It must be hard" \\
\hline \multicolumn{3}{|l|}{ Explicit, reducing space } \\
\hline Switching & Response that changes the frame of reference of the concern & "Did you have similar symptoms in the past?" \\
\hline Postponing & $\begin{array}{l}\text { Reducing space for talking about the concern at this } \\
\text { moment }\end{array}$ & "I would like to talk with you about this in a minute" \\
\hline Information advice & $\begin{array}{l}\text { Acknowledging concern, but giving information or advice } \\
\text { that does not open space for further disclosure }\end{array}$ & $\begin{array}{l}\text { "You do not need to worry, headaches are very } \\
\text { common" }\end{array}$ \\
\hline Active blocking & Mentioning concern and explicitly refusing to talk about it & "Worrying does not do you any good" \\
\hline \multicolumn{3}{|l|}{ Explicit, providing space } \\
\hline Content acknowledgement & $\begin{array}{l}\text { Echoing, reflecting back, giving paraphrases or summarizing } \\
\text { content of concern }\end{array}$ & "You've been experiencing headaches for a week now" \\
\hline Content exploration & Asking about content & "How long have you've been experiencing headaches?" \\
\hline Affect acknowledgement & $\begin{array}{l}\text { Echoing, reflecting back, giving paraphrases or summarizing } \\
\text { emotional aspects of concern }\end{array}$ & "You're worried" \\
\hline Affect exploration & Asking about emotional aspects & "Why are you worried?" \\
\hline Empathy & $\begin{array}{l}\text { Expression of feeling or understanding, with explicit reference } \\
\text { to the concern }\end{array}$ & "I understand that the pain is worrying you" \\
\hline
\end{tabular}

between the two periods, but the percentage of female GPs was higher in the second period (31\% versus $7 \%$ ).

\section{Expression of cues and concerns by patients in both periods}

In $92 \%$ of the consultations in this study, patients presented at least one cue or concern. The proportion of consultations containing at least one implicit cue did not differ between the two periods. However, the proportion of consultations containing at least one explicit concern was larger in the second period (see Table 4).

When looking at the timing of the cues and concerns expressed by patients, we see that the percentage of cues and concerns voiced during initial statements and exploration was higher in the first period compared to the second period. Patients more often expressed cues and concerns during the last phase of information and advice in more recent consultations (see Table 2).

Patients expressed on average 8.64 cues and 0.80 concerns per consultation. Because of the low frequencies of explicit concerns, we calculated estimated frequencies of voiced cues and concerns combined. When comparing these frequencies between the two periods, while controlling for patient characteristics and GP characteristics, we did not find significant changes. Since patient characteristics and GP characteristics differed between the two periods, we checked whether frequencies of expressed cues and concerns changed when running our models without the patient characteristics or the GP characteristics as covariates. Running the model without patient characteristics did not change our findings. However, we found that in the model without GP characteristics the number of cues and concerns in consultations involving psychological symptoms differed significantly between the two periods (Chi-square $=4.69, p<.05$ ). This indicates that differences in GP characteristics between the two study samples account for differences in the number of cues and concerns expressed by patients.

\section{GPs' responses to cues and concerns in both periods} In both periods, GPs' responses to cues and concerns were mostly characterized by giving space for patients 
Table 3 Characteristics of the study sample (consultations considered completely psychosocial by GPs)

\begin{tabular}{|c|c|c|c|}
\hline Patient and consultation characteristics & $1977-1989(\mathrm{~N}=121)$ & $1995-2008(\mathrm{~N}=391)$ & Comparison* \\
\hline Consultation duration & mean (sd) & mean (sd) & \\
\hline Duration & $11 \mathrm{~min}, 13 \mathrm{sec}$ & $14 \mathrm{~min}, 55 \mathrm{sec}$ & $t(510)=5.03^{* * *}$ \\
\hline Age & mean (sd) & mean $(s d)$ & \\
\hline Years & $38.2(16.0)$ & $44.6(17.7)$ & $t(510)=3.59^{* * *}$ \\
\hline Gender & N (\%) & $N(\%)$ & \\
\hline Male & $45(37 \%)$ & $128(33 \%)$ & $\operatorname{Chi}^{2}(1)=0.82$ \\
\hline 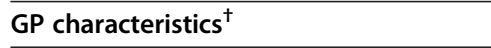 & $1977-1989(\mathrm{~N}=42)$ & $1995-2008(\mathrm{~N}=162)$ & \\
\hline Age & mean (sd) & mean (sd) & \\
\hline Years & $40.6(7.4)$ & $47.3(6.5)$ & $t(200)=5.76^{* * *}$ \\
\hline Gender & N (\%) & $N(\%)$ & \\
\hline Male & $39(93 \%)$ & $111(69 \%)$ & $\mathrm{Chi}^{2}(1)=10.15^{* *}$ \\
\hline Professional experience & mean (sd) & mean (sd) & \\
\hline Years working as a GP & $12.3(7.0)$ & $17.7(8.4)$ & $t(174)=3.69^{* * *}$ \\
\hline
\end{tabular}

${ }^{*}$ Analyzed with T-tests for continuous variables (consultation duration, age, professional experience) and Pearson's Chi ${ }^{2}$ for categorical variables (gender). ${ }^{*} p<0.05,{ }^{* *} p<0.01,{ }^{* * *} p<0.001$.

${ }^{\dagger}$ Age and working experience was missing for 2 GPs in the period 1977-1989. Working experience was missing for 26 GPs in the period 1995-2008. These data could not be recovered.

to talk about their concerns in a non-explicit way (see Table 5): being silent or giving minimal responses (back channels) were the most frequent ways for GPs to respond to cues and concerns. We did not find changes in response categories by GPs when comparing the two periods.

\section{Discussion}

Our study shows that patients are likely to express their worries during primary care psychosocial consultations and that the proportion of consultations with at least one explicit concern was higher during more recent consultations. The number of expressed cues and concerns

Table 4 Voiced cues and concerns by patients in both periods

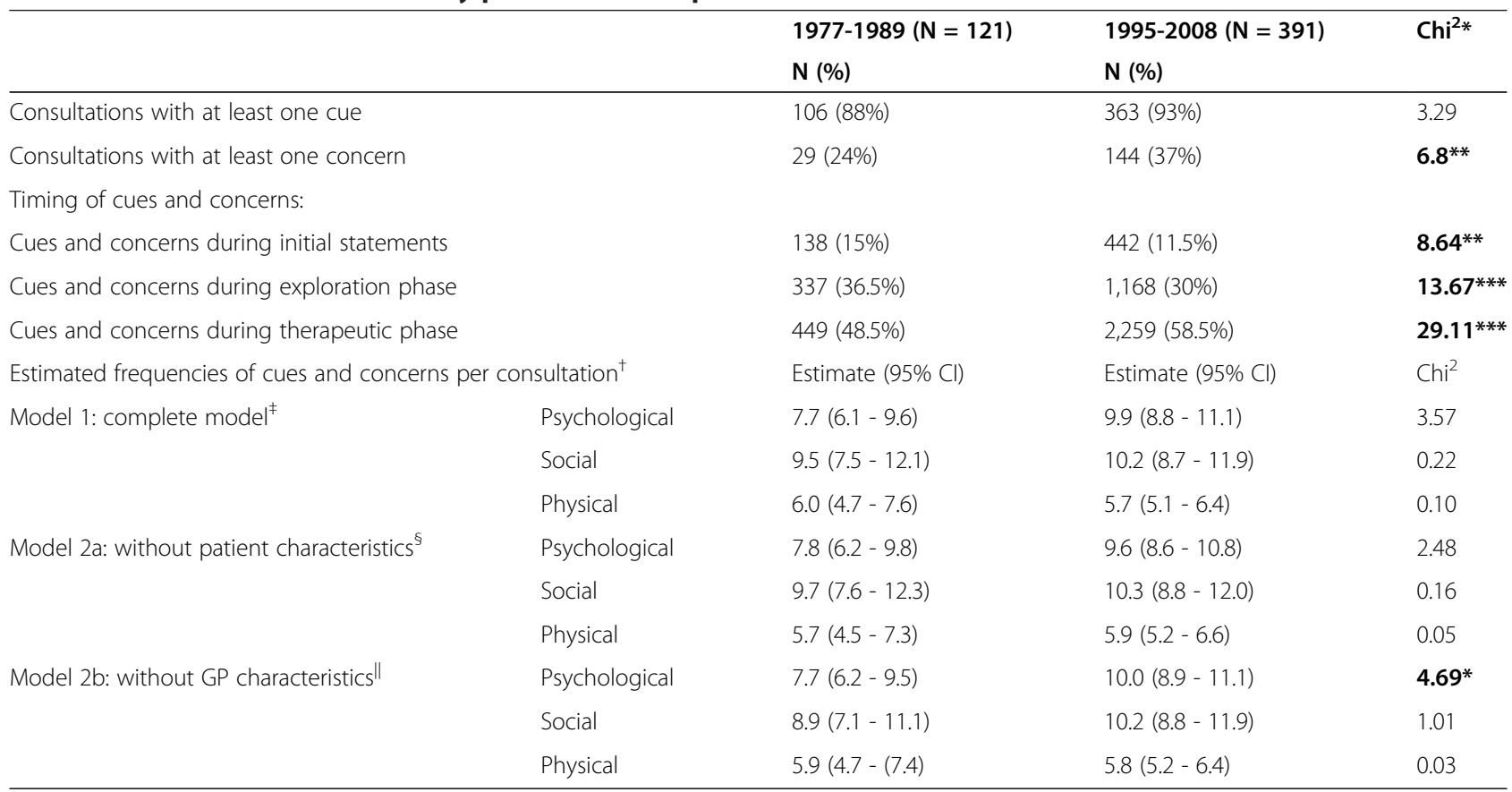

*Significant $\mathrm{Chi}^{2}$-tests indicate significant differences between the two periods, ${ }^{*} p<0.05,{ }^{* *} p<0.01$, ${ }^{* * *} p<0.001$.

${ }^{\dagger}$ Estimated with multilevel Poisson regression models.

${ }^{\ddagger}$ Included covariates: consultation duration, age of patient, gender of patient, age of GP, gender of GP.

§Included covariates: consultation duration, age of GP, gender of GP.

"Included covariates: consultation duration, age of patient, gender of patient. 
Table 5 Estimated frequencies of responses to cues and concerns by GPs

\begin{tabular}{|c|c|c|c|c|}
\hline & & $1977-1989^{*}$ & $1995-2008$ & $\mathrm{Chi}^{2 \neq}$ \\
\hline & & $(N=121)$ & $(\mathrm{N}=391)$ & \\
\hline & & Estimate $(95 \% \mathrm{Cl})$ & Eestimate $(95 \% \mathrm{Cl})$ & \\
\hline \multirow[t]{3}{*}{ Non-explicit, reducing space } & Psychological & $0.3(0.2-0.6)$ & $0.6(0.4-0.8)$ & 3.16 \\
\hline & Social & $0.5(0.2-0.8)$ & $0.5(0.3-0.8)$ & 0.01 \\
\hline & Physical & $0.6(0.4-1.1)$ & $0.4(0.3-0.5)$ & 3.04 \\
\hline \multirow[t]{3}{*}{ Non-explicit, providing space } & Psychological & $4.4(3.4-5.8)$ & $5.7(5.0-6.6)$ & 2.80 \\
\hline & Social & $6.1(4.6-8.1)$ & $6.7(5.5-8.1)$ & 0.24 \\
\hline & Physical & $3.4(2.5-4.5)$ & $3.3(2.9-3.8)$ & 0.00 \\
\hline \multirow[t]{3}{*}{ Explicit, reducing space } & Psychological & $1.0(0.7-1.4)$ & $1.2(0.9-1.4)$ & 0.47 \\
\hline & Social & $0.8(0.5-1.2)$ & $0.8(0.6-1.2)$ & 0.03 \\
\hline & Physical & $0.8(0.5-1.1)$ & $0.7(0.6-0.8)$ & 0.20 \\
\hline \multirow[t]{3}{*}{ Explicit, providing space } & Psychological & $1.4(1.0-2.1)$ & $1.7(1.4-2.1)$ & 0.69 \\
\hline & Social & $1.5(1.0-2.2)$ & $1.8(1.3-2.5)$ & 0.58 \\
\hline & Physical & $0.7(0.5-1.2)$ & $1.0(0.8-1.2)$ & 1.55 \\
\hline
\end{tabular}

*Estimated with multilevel Poisson regression models.

${ }^{+}$Included covariates: consultation duration, age of patient, gender of patient, age of GP, gender of GP.

${ }^{\ddagger}$ Significant $\mathrm{Chi}^{2}$-tests indicate significant differences between the two periods.

was partly explained by a change in GP characteristics; the latter sample contained more female GPs and more experienced GPs. Furthermore, we found that late-arising concerns were common in our study sample and were even more likely during more recent consultations. We found that GPs responded mostly by non-explicit communicative behavior, such as being silent or giving minimal responses to indicate that they were listening, but we did not find indications that GPs reduced the space for emotional disclosure.

\section{Patients' expressiveness}

In contrast to our expectations, we did not find a decrease in cues and concerns expressed by patients over time. Patients have become more familiar with psychosocial problems such as anxiety and depression and therefore may be more willing to open up about their concerns. Information on mental health has become readily available, for example through the Internet. Internet users seem to have high levels of mental health literacy and are well able to answer knowledge-based questions regarding psychological disorders [16]. Interestingly, although the proportion of explicitly expressed concerns increased over time, the number of expressions during consultations did not change. Patients' expressiveness has become somewhat more explicit, but not more extensive over time.

Patients tend to share their worries most often during the therapeutic phase as opposed to the initial or exploration phase of consultations. Late arising cues and concerns were more likely in recent consultations, compared to older consultations. With the introduction of clinical guidelines in the 1990s, more emphasis is placed on giving information and advice [1,2]. It is important that GPs are aware that providing new information to patients may also elicit new questions and concerns.

\section{Facilitating communication by GPs}

We found that the number of expressions of cues and concerns was partly dependent on GP characteristics. GPs in the second sample (1995-2008) were older, had more professional experience, were more often female, and were more likely to evoke more expressions of cues and concerns by patients. This is in line with previous research that shows that patients are more likely to share psychosocial issues and feel more empowered when talking to female GPs [17]. Accordingly, feminization of Dutch general practice care may partly account for changes in the way GPs facilitate communication about emotional issues.

Moreover, the GPs in our study were not likely to respond in an explicit way to patients' concerns, either by showing empathy or by further exploration of the worries voiced. This indicates that GPs remain relatively passive listeners, rather than actively providing emotional support for their patients. Studies in psychiatric settings show similar findings; physicians often hesitated to respond and were likely to respond with passive listening skills as opposed to engaging in active emotionfocused skills [18]. In some situations indirect responses to patients' emotions may be less intrusive and more adequate than explicit responses. However, active solicitation of concerns by GPs can prevent late arising, or even unvoiced, concerns [6]. Recent versions of clinical guidelines for depression and anxiety published in 2012 refer to 
the importance of empathy during consultations involving these psychological problems [19]. We consider this allusion to the importance of empathy in clinical guidelines as a positive development.

\section{Strengths and limitations of the study}

One of the strengths of this study is that we used the concerns and cues of patients as the starting point for our observations and analyses and focused on the patient's role. Furthermore, we examined consultations using videotaped real-life general practice consultations over a thirty-year period, enabling a comparison of doctor-patient communication prior to and after the introduction of national clinical guidelines in the 1990s. Video recording is a valid method of examining doctor-patient communication: the influence of the video recorder on participants is marginal [20] and the participants were unaware that the analyses would focus on psychosocial problems.

A possible weakness of the study is that we did not include consultations in which GPs were unable to recognize or identify psychosocial issues during consultations. We decided to only include consultations assessed by GPs as completely psychosocial, since we believe that cues and concerns by patients are most likely to be clearly expressed in these types of consultations. However, to be able to generalize the results to other health problems there is a need for replication studies within other consultation types, which may include more hidden psychosocial problems. Another limitation of our study is that we did not specify the nature and content of expressed cues and concerns by patients. Therefore, we do not know for each specific expressed cue or concern whether the patient was referring to psychosocial issues. However, due to the low frequency of the cues and concerns voiced, we decided to not further categorize these as this would complicate the interpretation of quantitative analyses and we could not guarantee interrater reliability. Furthermore, we only looked at immediate responses (lag 1) of GPs after patients' expressed cues and concerns; we did not include GPs' delayed or random empathic responses. This may explain why the previously found decline in empathy assessed over the entire consultation - was not found in the present study. We decided to look at lag 1 responses following expressed worries because we were interested in GPs immediate responsiveness; it can be argued that empathic responses are most appropriate and supportive when following directly after patients' expressed worries.

\section{Conclusions}

The aim of our study was to look at patients' expressed worries and GPs' immediate responses during psychosocial consultations in Dutch general practice. In earlier analyses, we found an increase in the proportion of consultations assessed by GPs as being mainly or completely psychosocial, while they gave less room for disclosing emotion-related issues. ${ }^{1}$ In the present study, we see that patients have become somewhat more open in expressing their concerns in recent years. We found that expression of worries is partly dependent on GP characteristics; experienced and female GPs were more likely to evoke more expressions of worries compared to less experienced and male GPs. With the changing GP population, the likelihood of expressing worries by patients seems to have changed.

While patients seem to have become somewhat more explicit in sharing their worries, GPs tend to respond mostly implicitly to these concerns. We argue that GPs should be encouraged to also respond explicitly to patients concerns, in order to ensure that patients feel heard and understood. Moreover, GPs need to be aware that concerns can appear throughout the consultation; towards the therapeutic phase of the consultation, new questions and concerns may arise, which also deserve full attention and appropriate responses from GPs.

\section{Abbreviations}

GP: General practitioner; GPs: General practitioners; VR-CoDES-CC: Verona coding definitions of emotional sequences - cues and concerns; VR-CoDES-P: Verona coding definitions of emotional sequences - provider's responses; ICPC: International Classification for Primary Care; ICC: Intraclass correlation.

\section{Competing interests}

The authors declare that they have no competing interests.

\section{Authors' contributions}

LB coordinated the coding of the videotaped consultations, formulated the study questions, discussed core ideas, analysed the data, and wrote the paper. PV designed the original study, discussed core ideas, and edited the paper. SvD discussed core ideas and edited the paper. JB designed the original study, discussed core ideas, and edited the paper. All authors read and approved the final manuscript.

\section{Acknowledgements}

We are grateful to the patients and general practitioners who participated in the studies and gave permission to videotape their medical visits.

Contributors: We would like to thank Doutzen Koopmans for coding the videotaped consultations, Richard van Kruysdijk for his technical support, and Peter Spreeuwenberg for his statistical advice. Funders This work was supported by the Dutch Ministry of Education, Culture and Science. The previous studies in which the consultations were recorded were financed by the Dutch Ministry of Health, Welfare and Sport, The Netherlands Organization for Health Research and Development (ZonMw), and the research fund of the Innovation Fund of Health Insurers (Innovatiefonds Zorgverzekeraars). The funding sources had no involvement in the study design, writing of the report, and the decision to submit the paper for publication.

\section{Author details}

NIVEL, Netherlands Institute for Health Services Research, Utrecht, The Netherlands. ${ }^{2}$ Department of General Practice, Faculty of Medical Sciences, University of Groningen, Groningen, The Netherlands. ${ }^{3}$ Department of Primary and Community Care, Radboud University Nijmegen Medical Center, Nijmegen, The Netherlands. ${ }^{4}$ Department of Health Sciences, Buskerud University College, Drammen, Norway. ${ }^{5}$ Department of Psychology, Faculty of Social and Behavioural Sciences, Utrecht University, Utrecht, The Netherlands. 
Received: 25 August 2014 Accepted: 7 November 2014

Published online: 25 November 2014

\section{References}

1. Butalid L, Bensing JM, Verhaak PFM: Talking about psychosocial problems: an observational study on changes in doctor-patient communication in general practice between 1977 and 2008. Patient Educ Couns 2014, 94:314-321.

2. Bensing JM, Tromp F, Van Dulmen S, Van den Brink-Muinen A, Verheul W, Schellevis FG: Shifts in doctor-patient communication between 1986 and 2002: a study of videotaped general practice consultations with hypertension patients. BMC Fam Pract 2006, 7:62-68.

3. Levinson W, Gorawara-Bath R, Lamb J: A study of patient clues and physician responses in primary care and surgical settings. JAMA 2000, 284:1021-1027.

4. Zimmermann C, Del Piccolo L, Finset A: Cues and concerns by patients in medical consultations: a literature review. Psychol Bull 2007, 133:438-463.

5. Eide $H$, Frankel R, Haaversen AC, Vaupel KA, Graugaard PK, Finset A: Listening for feelings: identifying and coding empathic and potential empathic opportunities in medical dialogues. Patient Educ Couns 2004 54:291-297.

6. White J, Levinson W, Roter D: Oh by the way: the closing moments of the medical visit. J Gen Intern Med 1994, 9:24-28.

7. Robinson JD: An interactional structure of medical activities during acute visits and its implications for patients' participation. Health Commun 2003, 15:27-57.

8. Verhaak PFM: Een evaluatie van de samenwerking tussen huisartsen en psycholoog in Capelle aan de IJssel [An evaluation of the cooperation between GPS and psychologist in Capelle aan de IJssel]. Utrecht: Nederlands Huisartsen Instituut; 1979

9. Bensing J: Doctor-patient communication and the quality of care. Soc Sci Med 1991, 32:1301-1310.

10. Bensing JM, Foets M, Van der Velden J, Van der Zee J: De Nationale Studie van ziekten en verrichtingen in de huisartspraktijk: achtergronden en methoden [The National Study of diseases and actions in general practice: background and methods]. Huisarts Wet 1991, 2:51-61.

11. Van den Brink-Muinen A, Verhaak PFM, Bensing JM, Bahrs O, Deveugele M, Gask L, Leiva F, Mead N, Messerli V, Oppizzi L, Peltenburg M, Perez A: Doctor-patient communication in different European health care systems: relevance and performance from the patients' perspective. Patient Educ Couns 2000, 1:115-127.

12. Van den Brink-Muinen A, Van Dulmen AM, Schellevis FG, Bensing JM: Tweede Nationale Studie naar ziekten en verrichtingen in de huisartspraktijk: oog voor communicatie: huisarts-patiënt communicatie in Nederland, [The second National Study of diseases and actions in general practice: an eye for communication: doctor-patient communication in the Netherlands]. Utrecht: NIVEL; 2004

13. Noordman J, Verhaak PFM, Van Beljouw I, Van Dulmen S: Consulting room computers and their effect on general practitioner-patient communication. Fam Pract 2010, 27:644-651.

14. Zimmermann C, Del Piccolo L, Bensing J, Bergvik S, De Haes H, Eide H, Fletcher I, Goss C, Heaven C, Humphris G, Kim YM, Langewitz W, Meeuwesen L, Nuebling M, Rimondini M, Salmon P, van Dulmen S, Wissow L, Zandbelt L, Finset A: Coding patient emotional cues and concerns in medical consultations: the Verona coding definitions of emotional sequences (VR-CoDES). Patient Educ Couns 2011, 82:141-148.

15. Del Piccolo L, de Haes H, Heaven C, Jansen J, Verheul W, Bensing J, Bergvik S, Deveugele M, Eide H, Fletcher I, Goss C, Humphris G, Kim YM, Langewitz W, Mazzi MA, Mjaaland T, Moretti F, Nübling M, Rimondini M, Salmon P, Sibbern T, Skre I, van Dulmen S, Wissow L, Young B, Zandbelt L, Zimmermann C, Finset A: Development of the Verona coding definitions of emotional sequences to code health providers' responses (VR-CoDES-P) to patient cues and concerns. Patient Educ Couns 2011, 82:149-155.

16. Lawlor E, Breslin JG, Renwick L, Foley S, Mulkerrin U, Kinsella A, Turner N, O'Callaghan E: Mental health literacy among Internet users. Early Interv Psychiatry 2008, 2:247-255.

17. Van den Brink-Muinen A, Van Dulmen AM, Messerli-Rohrbach V, Bensing JM: Do gender-dyads have different communication patterns? A comparative study in Western-European general practices. Patient Educ Couns 2002, 48:253-264
18. McCabe R, Heath C, Burns T, Prieve S: Engagement of patients with psychosis in the consultation: conversation analytic study. BMJ 2002, 325:1148-1151.

19. Nederlands Huisartsen Genootschap: NHG-standaarden. In https://www. nhg.org/nhg-standaarden.

20. Coleman T: Using video-recorded consultations for research in primary care: advantages and limitations. Fam Pract 2000, 17:422-427.

doi:10.1186/s12875-014-0188-3

Cite this article as: Butalid et al:: Concerns voiced by patients and GPs' responses during psychosocial visits in primary care: a historical cross-sectional study. BMC Family Practice 2014 15:188.

\section{Submit your next manuscript to BioMed Central and take full advantage of:}

- Convenient online submission

- Thorough peer review

- No space constraints or color figure charges

- Immediate publication on acceptance

- Inclusion in PubMed, CAS, Scopus and Google Scholar

- Research which is freely available for redistribution 